OPEN ACCESS

Edited by:

Nina Bhardwaj,

Icahn School of Medicine at Mount

Sinai, United States

Reviewed by:

Amir Horowitz,

Icahn School of Medicine at Mount

Sinai, United States

Domenico Mavilio,

Università degli Studi di Milano, Italy

*Correspondence:

Dimitra Peppa

d.peppa@ucl.ac.uk

Specialty section: This article was submitted to HIV and AIDS,

a section of the journal

Frontiers in Immunology

Received: 30 June 2017 Accepted: 29 September 2017 Published: 17 October 2017

Citation:

Peppa D (2017) Natural Killer Cells in Human Immunodeficiency Virus-1

Infection: Spotlight on the Impact of Human Cytomegalovirus.

Front. Immunol. 8:1322. doi: 10.3389/fimmu.2017.01322

\section{Natural Killer Cells in Human Immunodeficiency Virus-1 Infection: Spotlight on the Impact of Human Cytomegalovirus}

\author{
Dimitra Peppa ${ }^{1,2 *}$ \\ ${ }^{1}$ Division of Infection and Immunity, University College London, London, United Kingdom, ${ }^{2}$ Nuffield Department of Medicine, \\ University of Oxford, Oxford, United Kingdom
}

Human cytomegalovirus ( $\mathrm{HCMV}$ ) has been closely associated with the human race across evolutionary time. HCMV co-infection is nearly universal in human immunodeficiency virus-1 (HIV-1)-infected individuals and remains an important cofactor in HIV-1 disease progression even in the era of effective antiretroviral treatment. HCMV infection has been shown to have a broad and potent influence on the human immune system and has been linked with the discovery and characterization of adaptive natural killer (NK) cells. Distinct NK-cell subsets, predominately expressing the activating receptor NKG2C and the marker of terminal differentiation CD57, expand in response to HCMV. These NK-cell populations engaged in the long-lasting interaction with HCMV, in addition to characteristic but variable expression of surface receptors, exhibit reduced expression of signaling proteins and transcription factors expressed by canonical NK cells. Broad epigenetic modifications drive the emergence and persistence of HCMV-adapted NK cells that have distinct functional characteristics. NKG2C+ $\mathrm{NK}^{+}$-cell expansions have been observed in HIV-1 infected patients and other acute and chronic viral infections being systematically associated with HCMV seropositivity. The latter is potentially an important confounding variable in studies focused on the cellular NK-cell receptor repertoire and functional capacity. Here, focusing on HIV-1 infection we review the evidence in favor of "adaptive" changes likely induced by HCMV co-infection in NK-cell subsets. We highlight a number of key questions and how insights into the adaptive behavior of NK cells will inform new strategies exploiting their unique properties in the fight against HIV-1.

Keywords: human immunodeficiency virus, human cytomegalovirus, natural killer cells, NKG2C, CD57, adaptive

\section{INTRODUCTION}

Natural killer (NK) cells are a diverse group of innate lymphocytes residing at the crossroads of innate and adaptive immunity (1). Their remarkable effector agility is achieved via expression of a wide array of receptors and integration of signals that are finely attuned to ensure self-tolerance, while permitting effective responses against viral assaults and tumor transformation. In addition to important immunoregulatory functions $(2,3)$, a number of murine studies support that NK cells can acquire immunological memory similarly to B and T cells (4-7). While antigen-specific NK responses have been documented in mice and more recently in primates (8), clear evidence for NK-cell memory 
in humans is lacking. The NK-cell compartment in humans displays phenotypic and functional heterogeneity encompassing populations at various stages of maturation with distinct receptor combinations (9-11). In recent years, it has become apparent that variegated expression of inhibitory and activating receptors at the single cell level leads to a more diverse NK-cell repertoire than previously envisaged. Cytometry by time-of-flight has enabled us to profile the healthy human NK-cell repertoire, uncovering between 6,000 and 30,000 unique NK-cell subsets per individual (12). This observed diversity is generated by a combination of factors including genetic contributions $(13,14)$, along with differentiation in reprogramming in response to local tissue milieu (15) and infections/environmental factors (12). The substantial influence of environmental factors is supported by twin studies demonstrating that non-heritable factors exert a more profound and cumulative influence compared to heritable traits $(16,17)$. One such factor is human cytomegalovirus (HCMV), a widespread $\beta$-herpesvirus with a prevalence ranging from 40 to $100 \%$ depending on age, socioeconomic factors, and geographical region (18). In immunocompetent hosts, HCMV infection is usually subclinical leading to latency, whereas in immunosuppressed patients, including human immunodeficiency virus-1 (HIV-1)infected and transplant patients, it remains a significant cause of morbidity and potentially life threatening complications (18). HCMV has a broad impact on immunity (16) and has recently been associated with the expansion of adaptive or memory-like NK-cell subsets $(19,20)$.

In the context of HIV infection, HCMV is a highly prevalent (21) and well-recognized opportunistic pathogen responsible for significant morbidity and mortality prior to the introduction of antiretroviral treatment (ART) $(22,23)$. However, despite the roll-out of effective ART, HCMV remains a significant cofactor in HIV-1 disease progression (24-26), displaying a strong association with systemic inflammation $(27,28)$, cardiovascular disease $(29,30)$, reduced immune resilience (31), and immune senescence (27). A recent report has highlighted the role of HCMV replication in intestinal barrier dysfunction in asymptomatic HIV-1 infection and contribution to persistent immune activation (32). It is thus highly relevant to increase our understanding of the complex inter-relationship between HCMV and HIV-1 and of the effects that it bears on the effector immune response. The recent identification of distinct NK-cell subsets with adaptive properties induced by HCMV has raised a number of intriguing questions, including the ability of other viruses to induce them and their physiological relevance in different disease settings. Here, we summarize findings on the molecular signature of HCMV-adapted NK cells and discuss how NK-cell phenotypic and functional features described in HIV-1 infection could partly reflect the immunological fingerprint of HCMV.

\section{FEATURES OF CMV-ADAPTED NK CELLS-EMPHASIS ON HCMV}

Evidence from both murine and human studies has demonstrated an important role for NK cells in antiviral defense against herpesviruses, in particular HCMV (33), reinforced by elaborate viral evasion strategies (34).

Although NK cells have been originally described to represent short-lived innate lymphocytes, they can exhibit persistent memory in response to infections. This is best exemplified by mouse CMV (MCMV) infection, where naive NK cells that express Ly49H, recognizing the virally encoded glycoprotein $\mathrm{m} 157$, were reported to clonally expand and to subsequently contract forming a pool of long-lived memory cells (6). MCMVprimed memory NK cells mount a robust response upon secondary challenge with enhanced interferon- $\gamma($ IFN- $\gamma$ ) secretion and cytotoxicity (6), but display reduced "bystander" functionality to heterologous infection suggesting the specialized nature of these cells (35).

Congruent with animal models, HCMV infection has been shown to induce an adaptive reconfiguration of the NK-cell compartment. Seminal work by Lopez-Botet's group described a higher proportion of NK cells expressing the DAP-12 coupled NKG2C receptor in healthy individuals seropositive for HCMV $(36,37)$. These observations have been extended to hematopoietic stem cell transplantation $(38,39)$ and solid organ transplantation (40). Expansion of these subpopulations of NK cells and their subsequent longevity resembled clonal expansion of adaptive immune cells. Expanded NKG2C ${ }^{+} \mathrm{NK}$ cells display a differentiated phenotype characterized by expression of CD57, increased expression of the inhibitory $\operatorname{CD} 85 j(38,40)$, and a preferential oligoclonal pattern of inhibitory killer immunoglobulin receptors (KIRs) for self HLA-C1 and/or C2 allotypes $(41,42)$. In addition, they lack NKG2A, the inhibitory counterpart of NKG2C sharing specificity for HLA-E, and express lower levels of natural cytotoxicity receptors (NCR: NKp30 and NKp46) (36), CD161, CD7, and Siglec-7 (43-45) and have higher expression of CD2 involved in their activation $(46,47)$. Expression of other receptors such as NKG2D is maintained (36). The phenotypic hallmarks of adaptive NK cells are summarized in Figure 1. Of note, the magnitude of the HCMV imprint on NK-cell subsets varies within seropositive individuals (i.e., the $\mathrm{NKG} 2 \mathrm{C}^{\text {bright }}$ phenotype is found in $50 \%$ of $\mathrm{HCMV}^{+}$individuals) and the adaptive $\mathrm{NKG} 2 \mathrm{C}^{+}$compartment can persist in high frequencies for years (41). Subclinical or tissue specific reactivations of $\mathrm{HCMV}$ during latency may contribute to the maintenance of $\mathrm{NK}^{+} \mathrm{NKG} 2 \mathrm{C}^{+}$pool in addition to $\mathrm{NKG} 2 \mathrm{C}$ copy number and age-related changes in NK-cell differentiation $(48,49)$. The exact ligand involved in recognition and the cellular mechanisms driving the expansion of $\mathrm{NKG}_{2} \mathrm{C}^{+} \mathrm{NK}$ cells are yet to be elucidated. It remains unclear whether this is mediated through interaction with its cellular ligand HLA-E alone, HLA viral loaded peptide or an unknown ligand of host or viral origin (41, 50-52).

The large phenotypic heterogeneity of adaptive NK cells extending beyond the $\mathrm{NKG}_{2} \mathrm{C}^{+}$subset, is illustrated by the detection of NK-cell subsets sharing numerous attributes of adaptive NK cells in individuals independent of NKG2C or in the absence of NKG2C (KLRC2-deficient individuals) and in transplant recipients of NKG2C null grafts $(41,47,53)$. Strikingly, these HCMV-driven expansions encompass activating KIRs (53), suggesting their potential role in the recognition and response to HCMV. 
A Fully mature NK cell

B Memory-like/Adaptive NK cell
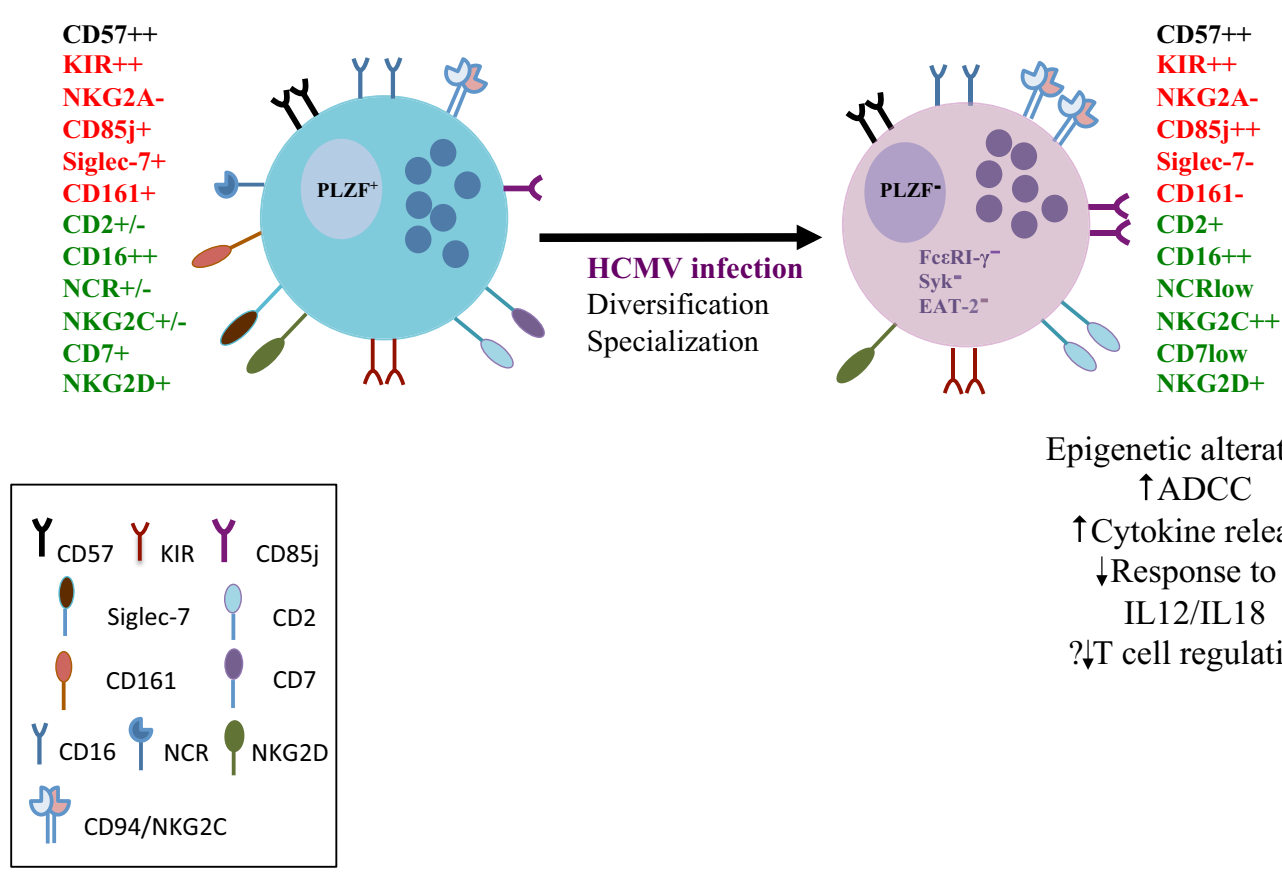

Epigenetic alterations

$\uparrow \mathrm{ADCC}$

$\uparrow$ Cytokine release

$\downarrow$ Response to

IL12/IL18

$? \downarrow T$ cell regulation

FIGURE 1 | The phenotypic, functional and molecular attributes of human cytomegalovirus (HCMV)-adapted natural killer (NK) cells. (A) As CD56dim NK cells go through the spectrum of differentiation they gradually lose expression of the inhibitory receptor NKG2A, natural cytotoxicity receptors and sequentially acquire more specific inhibitory receptors, such as inhibitory killer immunoglobulin receptors (KIRs) and CD85j. KIR acquisition is important in determining the functional fate of the NK cells. CD57 expression represents a terminal step in the differentiation process. Fully mature NK cells gain cytolytic ability and are efficient in mediating antibody-dependent cellular cytotoxicity (ADCC) (B) NK cells with adaptive features expanded in response to HCMV infection are distinct from conventional NK cells on the basis of expression of surface receptors, such as high expression of NKG2C, lower expression of the inhibitory Siglec-7, and down-regulation of the transcription factor promyelocytic leukemia zinc finger and key signaling molecules (FceRI- $\gamma$, Syk, and EAT-2). Different combinations of expression patterns result in considerable heterogeneity among adaptive NK cells. Epigenetic diversification leads to altered target cell specificities and functional specialization that includes enhanced ADCC (increased IFN- $\gamma$ and TNF- $\alpha$ against opsonized HCMV-infected targets) but reduced responsiveness to cytokine stimulation and reduced degranulation against autologous $\mathrm{T}$ cells. Red $=$ inhibitory receptors; green $=$ activating receptors.

Further reports described a subset of human NK cells deficient for the adaptor protein FceRI- $\gamma$, which was strongly associated with HCMV seropositivity (54). FceRI- $\gamma^{-}$NK cells share a lot of the characteristics of adaptive NK cells, respond robustly to $\mathrm{CD} 16$ stimulation (55) and similar to $\mathrm{NKG}^{+} \mathrm{C}^{+}$cells display more vigorous effector responses to HCMV-infected targets, but only in the presence of HCMV-specific antibodies $(54,56)$. NK cells lacking FceRI- $\gamma$ expand in response to HCMV-infected targets accentuated by the presence of anti-HCMV antibody, highlighting the role of specific humoral immunity in also favoring their preferential expansion (57-59). Interestingly, these cells also responded to herpes-simplex virus-1 (HSV1)-infected targets in the presence of HSV-1 plasma (54) demonstrating cross-protection to other viruses. The enhanced effector function of this subset was attributed to selective and more potent signaling through the $\mathrm{CD} 3 \zeta$ chain, which has three immunoreceptor tyrosine-based activation motifs. Subsequently, CD2 has been identified as a key co-stimulatory receptor synergizing with CD16 to stimulate increased cytokine production in adaptive NK cells (47). Global epigenetic profiling has identified commonalities between adaptive NK cells and memory CD8 T cells $(58,60)$. These adaptive NK cells are marked by DNA methylation silencing of the transcription factor, promyelocytic leukemia zinc finger (PLZF), as well as stochastic down-regulation of several signaling molecules, such as Syk, EAT-2, and DAB-2 $(58,60)$. PLZF is known to interact with several target genes, including IL12RB2, IL18RAP, and KLRB1 (61), explaining the lack of responsiveness to IL12/ IL18 stimulation (58). However, in comparison to conventional NK cells, adaptive NK cells display augmented IFN- $\gamma$ and TNF- $\alpha$ production when triggered via antibody-dependent cellular cytotoxicity (ADCC); the hypomethylated IFN- $\gamma$ and tumor necrosis factor (TNF) regulatory regions in adaptive NK cells provide a mechanism for increased cytokine production $(58,60)$. Interestingly, adaptive NK cells display reduced degranulation toward activated autologous $\mathrm{T}$ cells (58), which may impact on the regulation of immune responses.

Taken together, these results suggest the heterogeneity and functional specialization of adaptive NK cells in the immunosurveillance of infected cells and functional bias toward ADCC (Figure 1). Whereas the expansion of adaptive NK cells may serve as a strategy to control HCMV, during its life long interaction 
with the host, it remains unclear whether other viral infections can induce adaptive properties in NK cells. Although potential cross-reactivity of adaptive NK cells could confer an advantage in the tumor setting such as reduced relapse risk in leukemia patients $(62,63)$, their role in the control of heterologous infections or post vaccination is less well defined $(64,65)$.

\section{SKEWING AND ADAPTATION OF NK CELLS TO HIV-1 INFECTION: THE CONFOUNDING EFFECT OF HCMV}

Accumulating data support an important role for NK cells in the control of HIV-1 infection and protection against disease acquisition (66-68). These stem from elegant genetic studies linking specific KIR/HLA combinations with HIV-1 outcome $(66,67)$, functional studies where protective KIR alleles are associated with enhanced NK-cell cytolytic function in vitro (69) and evidence of KIR-facilitated immune pressure on HIV-1 to escape NK-cell recognition (70). However, chronic HIV-1 infection is known to alter NK-cell composition and effector function. This has been documented by a number of studies with often conflicting results, which can be attributed to a number of factors including the influence of immunogenetics, disease state, and the cross-sectional nature of studies. The latter have not always adequately controlled for a number of confounding factors such as age, gender, ethnicity, and HCMV serostatus among HIV-1-infected and HIV-1-negative controls. Given the high prevalence of HCMV co-infection within HIV cohorts and the profound skewing and adaptation of NK cells to HCMV, this is an important variable to consider when interpreting findings.

HIV-1 viremia is associated with a significant and pathological redistribution of the NK compartment with the emergence of an aberrant $\mathrm{CD}^{2} 6^{-} \mathrm{CD} 16^{+} \mathrm{NK}$-cell subset $(71,72)$. This rare population displays phenotypic perturbations, including downregulation of the activating NCRs, and features in common with mature CD56 ${ }^{\mathrm{dim}} \mathrm{NK}$ cells $(72,73)$. It has been proposed to represent an activated subset generated from chronic target engagement with impaired function. Recent studies have demonstrated that a decreased expression of the c-lectin-type inhibitory receptor, Siglec-7, on NK cells occurs early during HIV-1 infection and precedes the loss of CD56 (74). Expression of Siglec-7 is not affected in long-term non-progressors (LTNP), and ART leads to a progressive restoration of NK-cell subsets (74). Paralleling the observations in HIV-1 infection, HCMV reactivation in patients undergoing umbilical cord blood transplantation has been shown to induce the expansion of the CD56 ${ }^{-} / \mathrm{CD} 16^{+} /$Siglec- $7^{-} \mathrm{NK}$-cell subset (38). The expansion of hypofunctional CD56- $\mathrm{NK}$ cells following HCMV reactivation likely occurs when T-cell immunity is impaired and may also reflect the modulating effects of HCMV. It remains to be determined whether the $\mathrm{CD} 56^{-} / \mathrm{CD} 16^{+}$subset represents a subgroup of NK cells with adaptive features that has become anergic following repeated stimulation.

A number of other studies have reported a variable degree of perturbations in the NK-cell repertoire consistent with a dichotomous effect of viremia, including down-regulation of activating NK-cell receptors and up-regulation of expression of inhibitory NK receptors (iNKRs) (75-77). Collectively, these changes have been described to contribute to defective NK-cell function described in HIV-1 infection $(76,77)$. Although the HCMV serostatus is not always considered in these studies, it is plausible that these changes are biased by HCMV co-infection and possible reactivation with increasing immunosuppression. Along these lines, the observed down-regulation of NCRs, stable expression of NKG2D, and higher levels of CD85j and skewing of inhibitory KIRs (although not consistently reported) bear phenotypic resemblance to NK-cell subsets with adaptive features described in HCMV infection. NK cells in HIV-1 infection exhibit a higher ratio of $\mathrm{CD} 7^{+}$to $\mathrm{CD} 57^{-}$due to the loss of $\mathrm{CD}^{-} 7^{-}$cells in comparison to healthy controls; however, this comparison may be confounded by the HCMV status of these individuals, which was not reported (78). A shift toward a more mature terminally differentiated NK-cell phenotype is nonetheless supported by a study of HIV-1 infected individuals on effective ART, demonstrating that HCMV accelerates age-related increases in CD57 expression (79).

The most convincing evidence of the impact of HCMV coinfection on the NK-cell repertoire in HIV-1 infection comes from reports on NKG2C expression. Guma et al. originally proposed that HCMV co-infection is responsible for the expansions of NKG2 $\mathrm{C}^{+} \mathrm{NK}$ cells encountered in HIV-1 infected individuals (80). These findings were further supported by additional studies when the HCMV serostatus was taken into consideration $(81,82)$. The dramatic expansion of $\mathrm{NKG}_{2} \mathrm{C}^{+}$ $\mathrm{NK}$ cells in HIV-1 infected individuals was accompanied by a decrease in the expression of NKG2A leading to a low $\mathrm{NKG} 2 \mathrm{~A} / \mathrm{C}^{+} \mathrm{NK}$-cell ratio; these changes were attributed to concomitant infection and/or HCMV reactivation rather than being a consequence of HIV-1 infection alone (82). A number of reports describe $\mathrm{NKG}_{2} \mathrm{C}^{+} \mathrm{NK}$-cell expansions in several acute and chronic viral infections, being systematically associated with HCMV co-infection (83-86). Although the relative increase in the proportions of $\mathrm{NKG}_{2} \mathrm{C}^{+} \mathrm{NK}$ cells between HIV-1-infected and HIV-1-uninfected HCMV seropositive individuals varies between studies and cohorts $(80,81)$, the data suggest that the impact of HCMV exposure is potentially greater in HIV-1 infection. It has been suggested by animal models that the differentiation of adaptive NK cells is driven by inflammation (87). Thus, it is plausible that adaptive NK-cell expansions may be inflated in HIV-1 infected individuals, as a result of lack of immune control, ongoing immune activation and higher infectious burdens, including HCMV. One could speculate that the size of the HCMV imprint represents a compensatory mechanism in antiviral defense especially when T-cell-mediated control is impaired (88). It remains uncertain whether HCMV reactivation occurs alongside acute infection or alternatively whether pre-existing HCMV primed NK-cell subsets expand in response to secondary viral infection alone. HIV-1 causes down-regulation of HLA-A, B while retaining HLA-E expression $(89,90)$, similar to HCMV maintaining/ stabilizing HLA-E expression (91, 92). Thus, a direct effect of HIV-1 on NKG2C ${ }^{+} \mathrm{NK}$-cell expansion is conceivable. The 
recently reported down-regulation of HLA-C by most primary HIV-1 clones (93) raises questions about the ability of HCMV expanded $\mathrm{NKG}_{2} \mathrm{C}^{+} \mathrm{NK}$ cells, preferentially expressing selfHLA-C KIRs, to recognize "missing-self" on HIV-infected targets compared to mature educated NK cells.

Open questions remain regarding not only the mechanism but also the clinical implications of such HCMV-NK-cell interaction in terms of protection against acquisition and HIV-1 disease progression. NKG2C deletions have been linked to a higher risk of contracting HIV-1, in addition to accelerated disease progression and elevated pre-treatment viral load (94). Although these findings are interesting, this study did not report and correct for the influence of HCMV co-infection. One could speculate that the expansion of $\mathrm{NKG}_{2} \mathrm{C}^{+} \mathrm{NK}$ cells in HCMV seropositive individuals may confer protection against primary HIV-1; this notion is however not supported by some older observations that prior infection with HCMV is associated with low CD4 count, progression to AIDS and increased mortality (95). It has been suggested that maturation leads to divergence and increased NK-cell receptor diversity was found to be associated with an increased risk of HIV-1 acquisition in a small cohort of high-risk women (96). Given that viral challenge may increase receptor diversity, further work is required to determine whether this represents reduced plasticity to new challenging pathogens or whether it is linked to other immune characteristics such as exhaustion. Recently, a subpopulation of $\mathrm{PD}^{+} \mathrm{NK}$ cells, mainly composed of fully mature NK cells, has been described in $\mathrm{HCMV}^{+}$individuals (97). It would be of interest to assess whether NK cells expanded in HCMV/ HIV-1 co-infection succumb to continuous stimulation and examine the factors that may contribute to the induction of PD1 in this setting. PD1 signaling could therefore down-regulate not only T-cell-mediated responses but also innate responses, and this mechanism may be particularly prominent in HIV-1 infection (98).

Conversely, a link between a mature NK-cell compartment $\left(\mathrm{CD} 57^{+}\right)$and decreased levels of viral load and immune activation at the time of the primary HIV-1 infection has been reported. Those patients with a mature NK profile at inclusion showed a better early response to ART in comparison to patients with an immature NK profile (99). However, the HCMV serostatus of these individuals is not recorded and the status of NK cells at the point of infection is not known. Whether mature CD57 ${ }^{+}$ or $\mathrm{NKG}_{2} \mathrm{C}^{+} \mathrm{CD} 57^{+} \mathrm{NK}$ cells represent adaptive $\mathrm{NK}$ cells that contribute directly to better virus control during acute HIV-1 infection and how their role evolves during chronic infection remain unclear.

In agreement with the findings in HCMV seropositive individuals, an NK-cell population that lacks FceRI- $\gamma$ expression and has superior ADCC activity has been identified in HIV-1 viremic individuals and shown to persist following virological suppression with ART $(100,101)$. This subset shares some phenotypic characteristics with adaptive NK cells induced by HCMV (100). Although this subset is associated with HCMV antibody levels in the general population, in HIV-1-infected individuals correlates with inflammatory markers (100). The long-term effects of expansion of FceRI- $\gamma$-deficient NK cells in HIV-1 infection needs to be further elucidated given a possible role in tumor surveillance. Nonetheless, the identification of a subset with enhanced ADCC activity in HIV-1 infection has potentially important implications for the design of vaccine strategies aimed at generating ADCCpromoting antibody responses.

These collective data demonstrate that a number of the phenotypic NK-cell features described in HIV-1 bear the trademarks of HCMV infection (Figure 2). With increased definition of the assortment of NK-cell subsets with adaptive features driven by HCMV infection and the increased appreciation of HCMV in driving ongoing immune activation even during effective ART, it would be important to reassess the NK-cell repertoire composition, their response potential in different phases of infection and stimulus-dependent functional properties. A comprehensive analysis of the transcriptional signatures and epigenetic modifications of NK cells in HIV-1 infection is lacking and worth exploring.

\section{CONCLUDING REMARKS AND FUTURE PERSPECTIVES}

The potent effector function of NK cells and the rapidity of NK-cell response have identified them as key areas for research. Recent reports about the diversity of NK-cell repertoire and ability to assume adaptive features in response to HCMV infection and even display memory-like responses to cytokines (102) and antigen-specific responses in primates (8) have opened up prospects for the generation of new therapies. HCMV co-infection is highly prevalent in HIV-1 infected cohorts and remains an important cofactor in disease progression even in the era of ART. Both HIV-1 and HCMV as well as immune activation can further shape NK-cell responsiveness and differentiation. It is therefore important to capture the diversity of the NK-cell repertoire and identify potentially novel adaptive signatures of NK-cell subsets with preserved activation pathways. Whereas a number of questions remain regarding the epigenetic diversification,

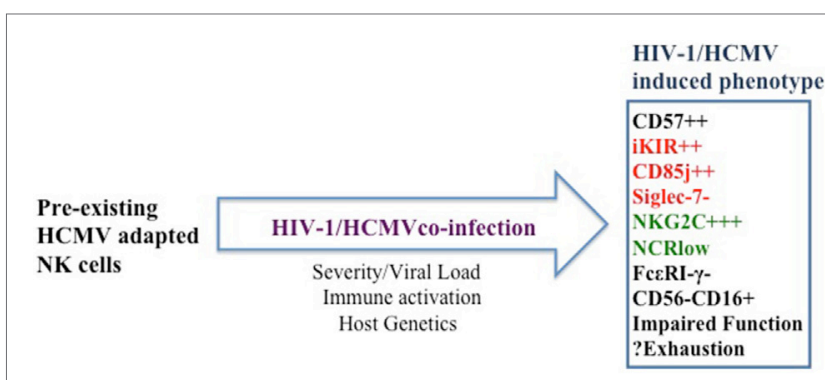

FIGURE 2 | Proposed model of the cumulative effect of human cytomegalovirus (HCMV) and ongoing immune activation on natural killer (NK) cells. Pre-existing HCMV-adapted NK cells expand during human immunodeficiency virus-1 infection to a variable degree depending on the tempo of HCMV reactivation, underlying level of immune activation, decreased T-cell-mediated control, and host genetics. HCMV co-infection accelerates NK-cell maturation and partly underlies the expansion of NK subsets with adaptive features in addition to the emergence of an aberrant CD56-CD16 ${ }^{+}$NK-cell subset. Whether these subsets become progressively dysregulated or exhausted remains to be determined. 
development, and persistence of NK cells with adaptive properties, elucidating how clonal NK-cell populations can be directed or reshaped will critically inform our ability to harness NK cells toward a therapeutic goal.

\section{AUTHOR CONTRIBUTIONS}

The author confirms being the sole contributor of this work and approved it for publication.

\section{REFERENCES}

1. Vivier E, Raulet DH, Moretta A, Caligiuri MA, Zitvogel L, Lanier LL, et al. Innate or adaptive immunity? The example of natural killer cells. Science (2011) 331(6013):44-9. doi:10.1126/science.1198687

2. Waggoner SN, Cornberg M, Selin LK, Welsh RM. Natural killer cells act as rheostats modulating antiviral T cells. Nature (2011) 481(7381):394-8. doi:10.1038/nature10624

3. Peppa D, Gill US, Reynolds G, Easom NJ, Pallett LJ, Schurich A, et al. Up-regulation of a death receptor renders antiviral $\mathrm{T}$ cells susceptible to NK cell-mediated deletion. J Exp Med (2013) 210(1):99-114. doi:10.1084/ jem.20121172

4. O'Leary JG, Goodarzi M, Drayton DL, von Andrian UH. T cell- and B cell-independent adaptive immunity mediated by natural killer cells. Nat Immunol (2006) 7(5):507-16. doi:10.1038/ni1332

5. Paust S, Gill HS, Wang BZ, Flynn MP, Moseman EA, Senman B, et al. Critical role for the chemokine receptor CXCR6 in NK cell-mediated antigen-specific memory of haptens and viruses. Nat Immunol (2010) 11(12):1127-35. doi: $10.1038 /$ ni. 1953

6. Sun JC, Beilke JN, Lanier LL. Adaptive immune features of natural killer cells. Nature (2009) 457(7229):557-61. doi:10.1038/nature07665

7. O’Sullivan TE, Sun JC, Lanier LL. Natural killer cell memory. Immunity (2015) 43(4):634-45. doi:10.1016/j.immuni.2015.09.013

8. Reeves RK, Li H, Jost S, Blass E, Li H, Schafer JL, et al. Antigen-specific NK cell memory in rhesus macaques. Nat Immunol (2015) 16(9):927-32. doi:10.1038/ni.3227

9. Lanier LL. NK cell recognition. Annu Rev Immunol (2005) 23:225-74. doi:10.1146/annurev.immunol.23.021704.115526

10. Moretta A, Bottino C, Vitale M, Pende D, Cantoni C, Mingari MC, et al. Activating receptors and coreceptors involved in human natural killer cell-mediated cytolysis. Annu Rev Immunol (2001) 19:197-223. doi:10.1146/ annurev.immunol.19.1.197

11. Caligiuri MA. Human natural killer cells. Blood (2008) 112(3):461-9. doi:10.1182/blood-2007-09-077438

12. Horowitz A, Strauss-Albee DM, Leipold M, Kubo J, Nemat-Gorgani N, Dogan OC, et al. Genetic and environmental determinants of human NK cell diversity revealed by mass cytometry. Sci Transl Med (2013) 5(208):208ra145. doi:10.1126/scitranslmed.3006702

13. Manser AR, Weinhold S, Uhrberg M. Human KIR repertoires: shaped by genetic diversity and evolution. Immunol Rev (2015) 267(1):178-96. doi:10.1111/imr.12316

14. Horowitz A, Djaoud Z, Nemat-Gorgani N, Blokhuis J, Hilton HG, Beziat $\mathrm{V}$, et al. Class I HLA haplotypes form two schools that educate NK cells in different ways. Sci Immunol (2016) 1(3):eaag1672. doi:10.1126/sciimmunol. aag 1672

15. Stegmann KA, Robertson F, Hansi N, Gill U, Pallant C, Christophides $\mathrm{T}$, et al. CXCR6 marks a novel subset of T-bet(lo)Eomes(hi) natural killer cells residing in human liver. Sci Rep (2016) 6:26157. doi:10.1038/ srep26157

16. Brodin P, Jojic V, Gao T, Bhattacharya S, Angel CJ, Furman D, et al. Variation in the human immune system is largely driven by non-heritable influences. Cell (2015) 160(1-2):37-47. doi:10.1016/j.cell.2014.12.020

17. Roederer M, Quaye L, Mangino M, Beddall MH, Mahnke Y, Chattopadhyay $\mathrm{P}$, et al. The genetic architecture of the human immune system: a bioresource

\section{ACKNOWLEDGMENTS}

My apologies to colleagues whose work could not be cited due to space limitations.

\section{FUNDING}

This work was supported by an MRC grant MR/M008614/1 awarded to DP.

for autoimmunity and disease pathogenesis. Cell (2015) 161(2):387-403. doi:10.1016/j.cell.2015.02.046

18. Griffiths P, Baraniak I, Reeves M. The pathogenesis of human cytomegalovirus. J Pathol (2015) 235(2):288-97. doi:10.1002/path.4437

19. Rolle A, Pollmann J, Cerwenka A. Memory of infections: an emerging role for natural killer cells. PLoS Pathog (2013) 9(9):e1003548. doi:10.1371/journal ppat. 1003548

20. Rolle A, Brodin P. Immune adaptation to environmental influence: the case of NK cells and HCMV. Trends Immunol (2016) 37(3):233-43. doi:10.1016/j. it.2016.01.005

21. Gianella S, Massanella M, Wertheim JO, Smith DM. The sordid affair between human herpesvirus and HIV. J Infect Dis (2015) 212(6):845-52. doi:10.1093/ infdis/jiv148

22. Emery VC. Investigation of CMV disease in immunocompromised patients. J Clin Pathol (2001) 54(2):84-8. doi:10.1136/jcp.54.2.84

23. Steininger C, Puchhammer-Stockl E, Popow-Kraupp T. Cytomegalovirus disease in the era of highly active antiretroviral therapy (HAART). J Clin Virol (2006) 37(1):1-9. doi:10.1016/j.jcv.2006.03.005

24. Patel EU, Gianella S, Newell K, Tobian AA, Kirkpatrick AR, Nalugoda F, et al. Elevated cytomegalovirus IgG antibody levels are associated with HIV-1 disease progression and immune activation. AIDS (2017) 31(6):807-13 doi:10.1097/QAD.0000000000001412

25. Deayton JR, Prof Sabin CA, Johnson MA, Emery VC, Wilson P, Griffiths PD. Importance of cytomegalovirus viraemia in risk of disease progression and death in HIV-infected patients receiving highly active antiretroviral therapy. Lancet (2004) 363(9427):2116-21. doi:10.1016/S0140-6736(04)16500-8

26. Adland E, Klenerman P, Goulder P, Matthews PC. Ongoing burden of disease and mortality from HIV/CMV coinfection in Africa in the antiretroviral therapy era. Front Microbiol (2015) 6:1016. doi:10.3389/fmicb.2015.01016

27. Freeman ML, Lederman MM, Gianella S. Partners in crime: the role of CMV in immune dysregulation and clinical outcome during HIV infection. Curr HIV/AIDS Rep (2016) 13(1):10-9. doi:10.1007/s11904-016-0297-9

28. Hunt PW. HIV and inflammation: mechanisms and consequences. Curr HIV/AIDS Rep (2012) 9(2):139-47. doi:10.1007/s11904-012-0118-8

29. Lichtner M, Cicconi P, Vita S, Cozzi-Lepri A, Galli M, Lo Caputo S, et al. Cytomegalovirus coinfection is associated with an increased risk of severe non-AIDS-defining events in a large cohort of HIV-infected patients. J Infect Dis (2015) 211(2):178-86. doi:10.1093/infdis/jiu417

30. Sacre K, Hunt PW, Hsue PY, Maidji E, Martin JN, Deeks SG, et al. A role for cytomegalovirus-specific CD4+CX3CR1+ T cells and cytomegalovirus-induced T-cell immunopathology in $\mathrm{HIV}$-associated atherosclerosis. AIDS (2012) 26(7):805-14. doi:10.1097/QAD.0b013e328351f780

31. Barrett L, Stapleton SN, Fudge NJ, Grant MD. Immune resilience in $\mathrm{HIV}$-infected individuals seronegative for cytomegalovirus. AIDS (2014) 28(14):2045-9. doi:10.1097/QAD.0000000000000405

32. Maidji E, Somsouk M, Rivera JM, Hunt PW, Stoddart CA. Replication of CMV in the gut of HIV-infected individuals and epithelial barrier dysfunction. PLoS Pathog (2017) 13(2):e1006202. doi:10.1371/journal.ppat.1006202

33. Biron CA, Byron KS, Sullivan JL. Severe herpesvirus infections in an adolescent without natural killer cells. N Engl J Med (1989) 320(26):1731-5 doi:10.1056/NEJM198906293202605

34. Noriega V, Redmann V, Gardner T, Tortorella D. Diverse immune evasion strategies by human cytomegalovirus. Immunol Res (2012) 54(1-3):140-51 doi:10.1007/s12026-012-8304-8 
35. Min-Oo G, Lanier LL. Cytomegalovirus generates long-lived antigen-specific NK cells with diminished bystander activation to heterologous infection. J Exp Med (2014) 211(13):2669-80. doi:10.1084/jem.20141172

36. Guma M, Angulo A, Vilches C, Gomez-Lozano N, Malats N, Lopez-Botet M. Imprint of human cytomegalovirus infection on the NK cell receptor repertoire. Blood (2004) 104(12):3664-71. doi:10.1182/blood-2004-05-2058

37. Guma M, Budt M, Saez A, Brckalo T, Hengel H, Angulo A, et al. Expansion of CD94/NKG2C+ NK cells in response to human cytomegalovirus-infected fibroblasts. Blood (2006) 107(9):3624-31. doi:10.1182/blood-2005-09-3682

38. Della Chiesa M, Falco M, Podesta M, Locatelli F, Moretta L, Frassoni F, et al. Phenotypic and functional heterogeneity of human NK cells developing after umbilical cord blood transplantation: a role for human cytomegalovirus? Blood (2012) 119(2):399-410. doi:10.1182/blood-2011-08-372003

39. Foley B, Cooley S, Verneris MR, Pitt M, Curtsinger J, Luo X, et al. Cytomegalovirus reactivation after allogeneic transplantation promotes a lasting increase in educated NKG2C+ natural killer cells with potent function. Blood (2012) 119(11):2665-74. doi:10.1182/blood-2011-10-386995

40. Lopez-Verges S, Milush JM, Schwartz BS, Pando MJ, Jarjoura J, York VA, et al. Expansion of a unique CD57(+)NKG2Chi natural killer cell subset during acute human cytomegalovirus infection. Proc Natl Acad Sci U S A (2011) 108(36):14725-32. doi:10.1073/pnas.1110900108

41. Beziat V, Liu LL, Malmberg JA, Ivarsson MA, Sohlberg E, Bjorklund AT, et al. NK cell responses to cytomegalovirus infection lead to stable imprints in the human KIR repertoire and involve activating KIRs. Blood (2013) 121(14):2678-88. doi:10.1182/blood-2012-10-459545

42. Djaoud Z, David G, Bressollette C, Willem C, Rettman P, Gagne K, et al. Amplified NKG2C+ NK cells in cytomegalovirus (CMV) infection preferentially express killer cell Ig-like receptor 2DL: functional impact in controlling CMV-infected dendritic cells. J Immunol (2013) 191(5):2708-16. doi:10.4049/jimmunol.1301138

43. Luetke-Eversloh M, Killig M, Romagnani C. Signatures of human NK cell development and terminal differentiation. Front Immunol (2013) 4:499. doi:10.3389/fimmu.2013.00499

44. Muntasell A, Vilches C, Angulo A, Lopez-Botet M. Adaptive reconfiguration of the human NK-cell compartment in response to cytomegalovirus: a different perspective of the host-pathogen interaction. Eur J Immunol (2013) 43(5):1133-41. doi:10.1002/eji.201243117

45. Beziat V, Dalgard O, Asselah T, Halfon P, Bedossa P, Boudifa A, et al. CMV drives clonal expansion of NKG2C+ NK cells expressing self-specific KIRs in chronic hepatitis patients. Eur J Immunol (2012) 42(2):447-57. doi:10.1002/ eji.201141826

46. Rolle A, Halenius A, Ewen EM, Cerwenka A, Hengel H, Momburg F. CD2-CD58 interactions are pivotal for the activation and function of adaptive natural killer cells in human cytomegalovirus infection. Eur J Immunol (2016) 46(10):2420-5. doi:10.1002/eji.201646492

47. Liu LL, Landskron J, Ask EH, Enqvist M, Sohlberg E, Traherne JA, et al. Critical role of $\mathrm{CD} 2$ co-stimulation in adaptive natural killer cell responses revealed in NKG2C-deficient humans. Cell Rep (2016) 15(5):1088-99. doi:10.1016/j.celrep.2016.04.005

48. Muntasell A, Lopez-Montanes M, Vera A, Heredia G, Romo N, Penafiel J, et al. NKG2C zygosity influences CD94/NKG2C receptor function and the NK-cell compartment redistribution in response to human cytomegalovirus. Eur J Immunol (2013) 43(12):3268-78. doi:10.1002/eji.201343773

49. Goodier MR, White MJ, Darboe A, Nielsen CM, Goncalves A, Bottomley C, et al. Rapid NK cell differentiation in a population with near-universal human cytomegalovirus infection is attenuated by NKG2C deletions. Blood (2014) 124(14):2213-22. doi:10.1182/blood-2014-05-576124

50. Rolle A, Pollmann J, Ewen EM, Le VT, Halenius A, Hengel H, et al. IL-12producing monocytes and HLA-E control HCMV-driven NKG2C+ NK cell expansion. J Clin Invest (2014) 124(12):5305-16. doi:10.1172/JCI77440

51. Lauterbach N, Wieten L, Popeijus HE, Voorter CE, Tilanus MG. HLA-E regulates $\mathrm{NKG} 2 \mathrm{C}+$ natural killer cell function through presentation of a restricted peptide repertoire. Hum Immunol (2015) 76(8):578-86. doi:10.1016/j.humimm.2015.09.003

52. Foley B, Cooley S, Verneris MR, Curtsinger J, Luo X, Waller EK, et al. Human cytomegalovirus (CMV)-induced memory-like NKG2C(+) NK cells are transplantable and expand in vivo in response to recipient CMV antigen. J Immunol (2012) 189(10):5082-8. doi:10.4049/jimmunol. 1201964
53. Della Chiesa M, Falco M, Bertaina A, Muccio L, Alicata C, Frassoni F, et al. Human cytomegalovirus infection promotes rapid maturation of NK cells expressing activating killer Ig-like receptor in patients transplanted with NKG2C-/- umbilical cord blood. J Immunol (2014) 192(4):1471-9. doi:10.4049/jimmunol.1302053

54. Zhang T, Scott JM, Hwang I, Kim S. Cutting edge: antibody-dependent memory-like NK cells distinguished by FcRgamma deficiency. J Immunol (2013) 190(4):1402-6. doi:10.4049/jimmunol.1203034

55. Hwang I, Zhang T, Scott JM, Kim AR, Lee T, Kakarla T, et al. Identification of human NK cells that are deficient for signaling adaptor FcRgamma and specialized for antibody-dependent immune functions. Int Immunol (2012) 24(12):793-802. doi:10.1093/intimm/dxs080

56. Wu Z, Sinzger C, Frascaroli G, Reichel J, Bayer C, Wang L, et al. Human cytomegalovirus-induced NKG2C(hi) CD57(hi) natural killer cells are effectors dependent on humoral antiviral immunity. J Virol (2013) 87(13):7717-25. doi:10.1128/JVI.01096-13

57. Lee J, Zhang T, Hwang I, Kim A, Nitschke L, Kim M, et al. Epigenetic modification and antibody-dependent expansion of memory-like NK cells in human cytomegalovirus-infected individuals. Immunity (2015) 42(3):431-42. doi:10.1016/j.immuni.2015.02.013

58. Schlums H, Cichocki F, Tesi B, Theorell J, Beziat V, Holmes TD, et al. Cytomegalovirus infection drives adaptive epigenetic diversification of NK cells with altered signaling and effector function. Immunity (2015) 42(3):443-56. doi:10.1016/j.immuni.2015.02.008

59. Costa-Garcia M, Vera A, Moraru M, Vilches C, Lopez-Botet M, Muntasell A. Antibody-mediated response of NKG2Cbright NK cells against human cytomegalovirus.J Immunol (2015) 194(6):2715-24. doi:10.4049/jimmunol.1402281

60. Luetke-Eversloh M, Hammer Q, Durek P, Nordstrom K, Gasparoni G, Pink $\mathrm{M}$, et al. Human cytomegalovirus drives epigenetic imprinting of the IFNG locus in NKG2Chi natural killer cells. PLoS Pathog (2014) 10(10):e1004441. doi:10.1371/journal.ppat.1004441

61. Gleimer M, von Boehmer H, Kreslavsky T. PLZF controls the expression of a limited number of genes essential for NKT cell function. Front Immunol (2012) 3:374. doi:10.3389/fimmu.2012.00374

62. Green ML, Leisenring WM, Xie H, Walter RB, Mielcarek M, Sandmaier BM, et al. CMV reactivation after allogeneic HCT and relapse risk: evidence for early protection in acute myeloid leukemia. Blood (2013) 122(7):1316-24. doi:10.1182/blood-2013-02-487074

63. Cichocki F, Cooley S, Davis Z, DeFor TE, Schlums H, Zhang B, et al. CD56dimCD57+NKG2C+ NK cell expansion is associated with reduced leukemia relapse after reduced intensity HCT. Leukemia (2016) 30(2):456-63. doi:10.1038/leu.2015.260

64. Nielsen CM, White MJ, Bottomley C, Lusa C, Rodriguez-Galan A, Turner SE, et al. Impaired NK cell responses to pertussis and H1N1 influenza vaccine antigens in human cytomegalovirus-infected individuals. J Immunol (2015) 194(10):4657-67. doi:10.4049/jimmunol.1403080

65. Darboe A, Danso E, Clarke E, Umesi A, Touray E, Wegmuller R, et al. Enhancement of cytokine-driven NK cell IFN-gamma production after vaccination of HCMV infected Africans. Eur J Immunol (2017) 47(6):1040-50. doi:10.1002/eji.201746974

66. Martin MP, Gao X, Lee JH, Nelson GW, Detels R, Goedert JJ, et al. Epistatic interaction between KIR3DS1 and HLA-B delays the progression to AIDS. Nat Genet (2002) 31(4):429-34. doi:10.1038/ng934

67. Martin MP, Qi Y, Gao X, Yamada E, Martin JN, Pereyra F, et al. Innate partnership of HLA-B and KIR3DL1 subtypes against HIV-1. Nat Genet (2007) 39(6):733-40. doi:10.1038/ng2035

68. Boulet S, Kleyman M, Kim JY, Kamya P, Sharafi S, Simic N, et al. A combined genotype of KIR3DL1 high expressing alleles and HLA-B ${ }^{\star} 57$ is associated with a reduced risk of HIV infection. AIDS (2008) 22(12):1487-91. doi:10.1097/QAD.0b013e3282ffde7e

69. Alter G, Martin MP, Teigen N, Carr WH, Suscovich TJ, Schneidewind A, et al. Differential natural killer cell-mediated inhibition of HIV-1 replication based on distinct KIR/HLA subtypes. J Exp Med (2007) 204(12):3027-36. doi:10.1084/jem.20070695

70. Alter G, Heckerman D, Schneidewind A, Fadda L, Kadie CM, Carlson JM, et al. HIV-1 adaptation to NK-cell-mediated immune pressure. Nature (2011) 476(7358):96-100. doi:10.1038/nature10237

71. Alter G, Teigen N, Davis BT, Addo MM, Suscovich TJ, Waring MT, et al. Sequential deregulation of NK cell subset distribution and function 
starting in acute HIV-1 infection. Blood (2005) 106(10):3366-9. doi:10.1182/ blood-2005-03-1100

72. Mavilio D, Lombardo G, Benjamin J, Kim D, Follman D, Marcenaro E, et al. Characterization of CD56-/CD16+ natural killer (NK) cells: a highly dysfunctional NK subset expanded in HIV-infected viremic individuals. Proc Natl Acad Sci U S A (2005) 102(8):2886-91. doi:10.1073/pnas.0409872102

73. Milush JM, Lopez-Verges S, York VA, Deeks SG, Martin JN, Hecht FM, et al. CD56negCD16(+) NK cells are activated mature NK cells with impaired effector function during HIV-1 infection. Retrovirology (2013) 10:158. doi:10.1186/1742-4690-10-158

74. Brunetta E, Fogli M, Varchetta S, Bozzo L, Hudspeth KL, Marcenaro E, et al. The decreased expression of Siglec-7 represents an early marker of dysfunctional natural killer-cell subsets associated with high levels of HIV-1 viremia. Blood (2009) 114(18):3822-30. doi:10.1182/blood-2009-06-226332

75. Mavilio D, Benjamin J, Daucher M, Lombardo G, Kottilil S, Planta MA, et al. Natural killer cells in HIV-1 infection: dichotomous effects of viremia on inhibitory and activating receptors and their functional correlates. Proc Natl Acad Sci U S A (2003) 100(25):15011-6. doi:10.1073/pnas.2336091100

76. Fauci AS, Mavilio D, Kottilil S. NK cells in HIV infection: paradigm for protection or targets for ambush. Nat Rev Immunol (2005) 5(11):835-43. doi:10.1038/nri1760

77. Ansari AW, Ahmad F, Meyer-Olson D, Kamarulzaman A, Jacobs R, Schmidt RE. Natural killer cell heterogeneity: cellular dysfunction and significance in HIV-1 immuno-pathogenesis. Cell Mol Life Sci (2015) 72(16):3037-49. doi:10.1007/s00018-015-1911-5

78. Hong HS, Eberhard JM, Keudel P, Bollmann BA, Ballmaier M, Bhatnagar N, et al. HIV infection is associated with a preferential decline in less-differentiated CD56dim CD16+ NK cells. J Virol (2010) 84(2):1183-8. doi:10.1128/ JVI.01675-09

79. Affandi JS, Montgomery J, Brunt SJ, Nolan D, Price P. The immunological footprint of CMV in HIV-1 patients stable on long-term ART. Immun Ageing (2015) 12:14. doi:10.1186/s12979-015-0041-0

80. Guma M, Cabrera C, Erkizia I, Bofill M, Clotet B, Ruiz L, et al. Human cytomegalovirus infection is associated with increased proportions of NK cells that express the CD94/NKG2C receptor in aviremic HIV-1-positive patients. J Infect Dis (2006) 194(1):38-41. doi:10.1086/504719

81. Mela CM, Goodier MR. The contribution of cytomegalovirus to changes in NK cell receptor expression in HIV-1-infected individuals. J Infect Dis (2007) 195(1):158-9; author reply 9-60. doi:10.1086/509811

82. Brunetta E, Fogli M, Varchetta S, Bozzo L, Hudspeth KL, Marcenaro E, et al. Chronic HIV-1 viremia reverses NKG2A/NKG2C ratio on natural killer cells in patients with human cytomegalovirus co-infection. AIDS (2010) 24(1):27-34. doi:10.1097/QAD.0b013e3283328d1f

83. Bjorkstrom NK, Lindgren T, Stoltz M, Fauriat C, Braun M, Evander M, et al. Rapid expansion and long-term persistence of elevated NK cell numbers in humans infected with hantavirus. JExp Med (2011) 208(1):13-21. doi:10.1084/jem.20100762

84. Petitdemange C, Becquart P, Wauquier N, Beziat V, Debre P, Leroy EM, et al. Unconventional repertoire profile is imprinted during acute chikungunya infection for natural killer cells polarization toward cytotoxicity. PLoS Pathog (2011) 7(9):e1002268. doi:10.1371/journal.ppat.1002268

85. Saghafian-Hedengren S, Sohlberg E, Theorell J, Carvalho-Queiroz C, Nagy $\mathrm{N}$, Persson JO, et al. Epstein-Barr virus coinfection in children boosts cytomegalovirus-induced differentiation of natural killer cells. J Virol (2013) 87(24):13446-55. doi:10.1128/JVI.02382-13

86. Malone DFG, Lunemann S, Hengst J, Ljunggren HG, Manns MP, Sandberg $\mathrm{JK}$, et al. Cytomegalovirus-driven adaptive-like natural killer cell expansions are unaffected by concurrent chronic hepatitis virus infections. Front Immunol (2017) 8:525. doi:10.3389/fimmu.2017.00525

87. Sun JC, Madera S, Bezman NA, Beilke JN, Kaplan MH, Lanier LL. Proinflammatory cytokine signaling required for the generation of natural killer cell memory. J Exp Med (2012) 209(5):947-54. doi:10.1084/ jem. 20111760

88. Kuijpers TW, Baars PA, Dantin C, van den Burg M, van Lier RA, Roosnek E. Human NK cells can control CMV infection in the absence of T cells. Blood (2008) 112(3):914-5. doi:10.1182/blood-2008-05-157354
89. Cohen GB, Gandhi RT, Davis DM, Mandelboim O, Chen BK, Strominger JL, et al. The selective downregulation of class I major histocompatibility complex proteins by HIV-1 protects HIV-infected cells from NK cells. Immunity (1999) 10(6):661-71. doi:10.1016/S1074-7613(00)80065-5

90. Nattermann J, Nischalke HD, Hofmeister V, Kupfer B, Ahlenstiel G, Feldmann G, et al. HIV-1 infection leads to increased HLA-E expression resulting in impaired function of natural killer cells. Antivir Ther (2005) 10(1):95-107.

91. Tomasec P, Braud VM, Rickards C, Powell MB, McSharry BP, Gadola S, et al. Surface expression of HLA-E, an inhibitor of natural killer cells, enhanced by human cytomegalovirus gpUL40. Science (2000) 287(5455):1031. doi:10.1126/science.287.5455.1031

92. Djaoud Z, Riou R, Gavlovsky PJ, Mehlal S, Bressollette C, Gerard N, et al. Cytomegalovirus-infected primary endothelial cells trigger NKG2C+ natural killer cells. J Innate Immun (2016) 8(4):374-85. doi:10.1159/000445320

93. Apps R, Del Prete GQ, Chatterjee P, Lara A, Brumme ZL, Brockman MA, et al. HIV-1 Vpu mediates HLA-C downregulation. Cell Host Microbe (2016) 19(5):686-95. doi:10.1016/j.chom.2016.04.005

94. Thomas R, Low HZ, Kniesch K, Jacobs R, Schmidt RE, Witte T. NKG2C deletion is a risk factor of HIV infection. AIDS Res Hum Retroviruses (2012) 28(8):844-51. doi:10.1089/AID.2011.0253

95. Sabin CA, Phillips AN, Lee CA, Janossy G, Emery V, Griffiths PD. The effect of $\mathrm{CMV}$ infection on progression of human immunodeficiency virus disease is a cohort of haemophilic men followed for up to 13 years from seroconversion. Epidemiol Infect (1995) 114(2):361-72. doi:10.1017/S095026880005799X

96. Strauss-Albee DM, Fukuyama J, Liang EC, Yao Y, Jarrell JA, Drake AL, et al. Human NK cell repertoire diversity reflects immune experience and correlates with viral susceptibility. Sci Transl Med (2015) 7(297):297ra115. doi:10.1126/scitranslmed.aac5722

97. Pesce S, Greppi M, Tabellini G, Rampinelli F, Parolini S, Olive D, et al. Identification of a subset of human natural killer cells expressing high levels of programmed death 1: a phenotypic and functional characterization. J Allergy Clin Immunol (2017) 139(1):335-46.e3. doi:10.1016/j.jaci.2016. 04.025

98. Norris S, Coleman A, Kuri-Cervantes L, Bower M, Nelson M, Goodier MR. PD-1 expression on natural killer cells and CD8(+) T cells during chronic HIV-1 infection. Viral Immunol (2012) 25(4):329-32. doi:10.1089/ vim.2011.0096

99. Gondois-Rey F, Cheret A, Mallet F, Bidaut G, Granjeaud S, Lecuroux C, et al. A mature NK profile at the time of HIV primary infection is associated with an early response to cART. Front Immunol (2017) 8:54. doi:10.3389/ fimmu.2017.00054

100. Zhou J, Amran FS, Kramski M, Angelovich TA, Elliott J, Hearps AC, et al. An NK cell population lacking FcRgamma is expanded in chronically infected HIV patients. J Immunol (2015) 194(10):4688-97. doi:10.4049/ jimmunol.1402448

101. Hearps AC, Agius PA, Zhou J, Brunt S, Chachage M, Angelovich TA, et al. Persistence of activated and adaptive-like NK cells in HIV+ individuals despite 2 years of suppressive combination antiretroviral therapy. Front Immunol (2017) 8:731. doi:10.3389/fimmu.2017.00731

102. Cooper MA, Elliott JM, Keyel PA, Yang L, Carrero JA, Yokoyama WM. Cytokine-induced memory-like natural killer cells. Proc Natl Acad Sci U S A (2009) 106(6):1915-9. doi:10.1073/pnas.0813192106

Conflict of Interest Statement: The author declares that the research was conducted in the absence of any commercial or financial relationships that could be construed as a potential conflict of interest.

The reviewer $\mathrm{AH}$ and handling editor declared their shared affiliation.

Copyright $\odot 2017$ Peppa. This is an open-access article distributed under the terms of the Creative Commons Attribution License (CC BY). The use, distribution or reproduction in other forums is permitted, provided the original author(s) or licensor are credited and that the original publication in this journal is cited, in accordance with accepted academic practice. No use, distribution or reproduction is permitted which does not comply with these terms. 